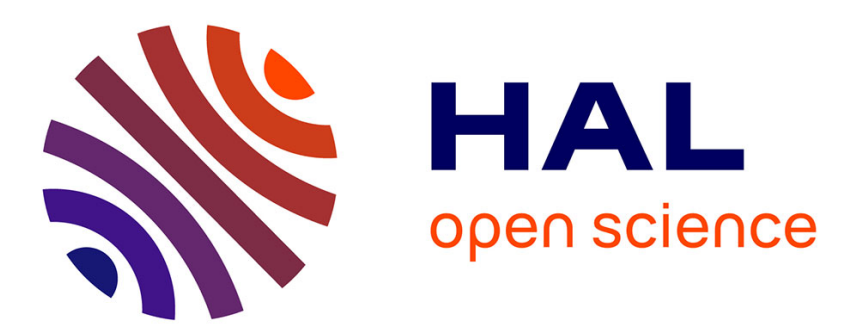

\title{
Effect of loading rate on the plane stress fracture toughness properties of an aluminum alloy \\ H. Couque
}

\section{To cite this version:}

H. Couque. Effect of loading rate on the plane stress fracture toughness properties of an aluminum alloy. Journal de Physique IV Proceedings, 1994, 04 (C8), pp.C8-747-C8-752. 10.1051/jp4:19948115 . jpa-00253357

\section{HAL Id: jpa-00253357 https://hal.science/jpa-00253357}

Submitted on 1 Jan 1994

HAL is a multi-disciplinary open access archive for the deposit and dissemination of scientific research documents, whether they are published or not. The documents may come from teaching and research institutions in France or abroad, or from public or private research centers.
L'archive ouverte pluridisciplinaire HAL, est destinée au dépôt et à la diffusion de documents scientifiques de niveau recherche, publiés ou non, émanant des établissements d'enseignement et de recherche français ou étrangers, des laboratoires publics ou privés. 


\title{
Effect of loading rate on the plane stress fracture toughness properties of an aluminum alloy
}

H. Couque

Southwest Research Institute, 6220 Culebra Road, San Antonio, Texas 78228, U.S.A.

Résumé: L'effet de la vitesse de chargement sur les propriétés de ténacité en contrainte plane de plaques de $3.2 \mathrm{~mm}$ d'épaisseur en alliage d'aluminium 2219-T87 a été examiné à l'aide d'échantillons de traction à fissure centrale. Des courbes J de résistance à la rupture ont été obtenues à des vitesses de déplacements de $10^{-6}$ et 5.7 $\mathrm{m} \mathrm{s}^{-1}$. L'essai dynamique de rupture fut conduit avec des plaques de pression couplées (coupled pressure plates). Les résultats montrent que les ténacités d'initiation et de propagation augmentent avec l'accroissement de la vitesse de chargement. Il est montré que l'augmentation de la ténacité est liée aux propriétés de la contrainte en fonction de la vitesse de déformation et au comportement ductile intrinsèque de l'alliage d'aluminium.

\begin{abstract}
The effect of loading rate on the plane stress fracture toughness properties of a 3.2-mm thick 2219-T87 aluminum alloy plate was investigated with center-cracked panels. Plane-stress J-resistance curves were generated at a constant displacement rate of $10^{-6}$ and $5.7 \mathrm{~m} \mathrm{~s}^{-1}$. Dynamic fracture testing was performed with a coupled pressure plates technique. Fracture initiation and propagation toughnesses were found to increase with an increased loading rate. The toughness increase was found to be related to the rate sensitivity characteristics and intrinsic ductile behavior of the aluminum alloy.
\end{abstract}

\section{INTRODUCTION}

Nothing is available in the literature regarding the dynamic plane stress fracture toughness of aluminum alloys because dynamic conditions are very rare in conventional aluminum structures made of sheets and plates. Hence, it is only recently that a need has arisen to establish if the plane stress fracture toughness of aluminum increases with increasing loading rate. This information is needed for integrity studies of aluminum space station pressure vessels against hypervelocity impact from meteoroids and orbital debris, the development of aluminum-hardened aircraft fuselages, and the mass production of aluminum vehicles. Some information is available from tensile testing to strain rates of $1.5 \times 10^{3} \mathrm{~s}^{-1}$ and from uniaxial stress state compression testing to strain rates of $3 \times 10^{3} \mathrm{~s}^{-1}$ of conventional aluminum alloys [1-5]. Under these conditions, these alloys exhibit a higher flow stress when compared to quasi-static loading conditions, particularly for low-strength aluminum alloys. It was anticipated that the intermediate-strength aluminum alloy 2219-T87 being considered in this study would exhibit mechanical responses that are dependent on loading rate. It was also anticipated that the dynamic fracture toughness would be significant because aluminum alloys are known to fail via void growth and coalescence which, based on in-depth material studies like those as steel, implies an increase of the toughness with the increase in loading rate [6].

To investigate these hypotheses a special experimental procedure was developed to enable reliable comparison of the quasi-static and dynamic J-resistance (J-R) curves of a $3.2 \mathrm{~mm}$ thick 2219-T87 aluminum alloy plates selected for the inhabited modules of the proposed NASA space station. Fracture testing was conducted at a constant displacement rate of $10^{-6}$ and $5.7 \mathrm{~m} \mathrm{~s}^{-1}$ using prefatigued, center-cracked panel specimens, $76 \mathrm{~mm}$ in planar size. Under dynamic conditions, displacement-controlled loading conditions were achieved with a coupled pressure plates (CPP) technique. Details of the specific experimental conditions and instrumentation are provided in the next section. The fracture toughness data are then given and discussed based on tensile data and observed fracture processes [7]. 


\section{EXPERIMENTAL PROCEDURE}

\subsection{Material}

A 2219-T87 aluminum alloy composed of equiaxial grains $905 \mu \mathrm{m}$ long and $120 \mu \mathrm{m}$ wide was employed. The alloy tensile characteristics as a function of strain rate are given in Reference [7] and are summarized in Figure 1. With the increase of the strain rate from $10^{-4}$ to $1.5 \times 10^{3} \mathrm{~s}^{-1}$, the ultimate tensile strength increases by $12 \%$. Fracture properties were generated to address rapid Mode I fracture in the axial direction of the space station modules. Since the space station modules will be made of cylindrical plates with the rolling direction parallel to the hoop direction, Mode I fracture properties were characterized in the direction perpendicular to the rolling direction (TL).

\subsection{Plane Stress Fracture Testing Procedure}

Quasi-static and dynamic fracture tests were conducted at a constant far-field displacement rate using prefatigued center-cracked panels shown in Figure 2. The specimens designed to prevent crack-tip buckling [7] had a planar length dimension, $W$, of $76.2 \mathrm{~mm}$, a total prefatigued crack length, $2 \mathrm{a}_{0}$, of $32.5 \mathrm{~mm}$, and a total effective height between grips, $2 h_{e}$, of $50.8 \mathrm{~mm}$. Because the specimens were prefatigued, crack initiation toughness data were obtained along with crack propagation toughness.

Quasi-static plane stress fracture testing was performed at a constant displacement rate of $10^{-6} \mathrm{~m} \mathrm{~s}^{-1}$. Two strain gages were mounted over the specimen ligament to monitor the crack initiation and propagation event. Physical crack growth data were generated from compliance measurements [8].

Dynamic plane stress fracture testing was conducted using the CPP technique. Unique to this technique is the ability to provide a constant displacement rate simultaneously to two center-cracked specimens. The CPP technique was derived from a dynamic plane strain fracture test, the coupled pressure bars (CPB) technique [9], which was successfully applied to dynamic initiation and dynamic propagation toughnesses characterization of a structural 4340 steel [10]. A schematic of the CPP experiment is shown in Figure 3. The primary components consist of two pressure plates to store energy, a notched, round, starter specimen to rapidly release the stored energy, and two prefatigued, center-cracked specimens. Before securing the specimens to the apparatus, the pressure plates and starter specimen are preloaded to $222 \mathrm{kN}$, corresponding to a plate applied stress of $87 \mathrm{MPa}$. The specimens were then secured to the pressure plates using $51 \mathrm{~mm}$ height grips. Strain measurements near the grips were conducted prior and after gripping to verify that the specimens were in the unloaded condition after gripping. Fracture of the starter specimen was subsequently initiated by introducing a sharp cut into the circumferential notch of the starter specimen using a cutter wheel and high-speed air drill. Failure of the starter specimen releases the unloading stress wave from the plates which transmits a rapid constant axial displacement rate to the specimens.

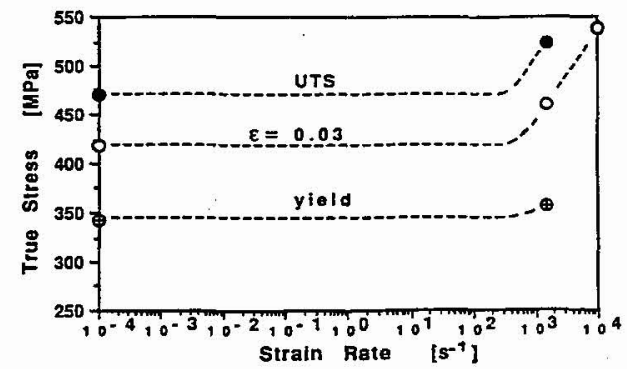

Figure 1. Tensile flow properties as a function of strain rate of the $3.2 \mathrm{~mm}$ thick $2219-\mathrm{T} 87$ aluminum alloy plate.

a)

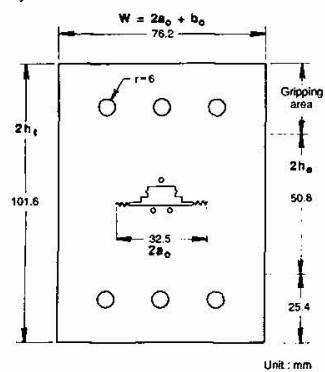

b)

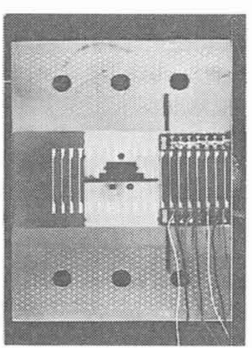

Figure 2. Center-cracked panel specimens: a) specimen planar sizes, b) specimen partially instrumented showing installed crack gages on one side.

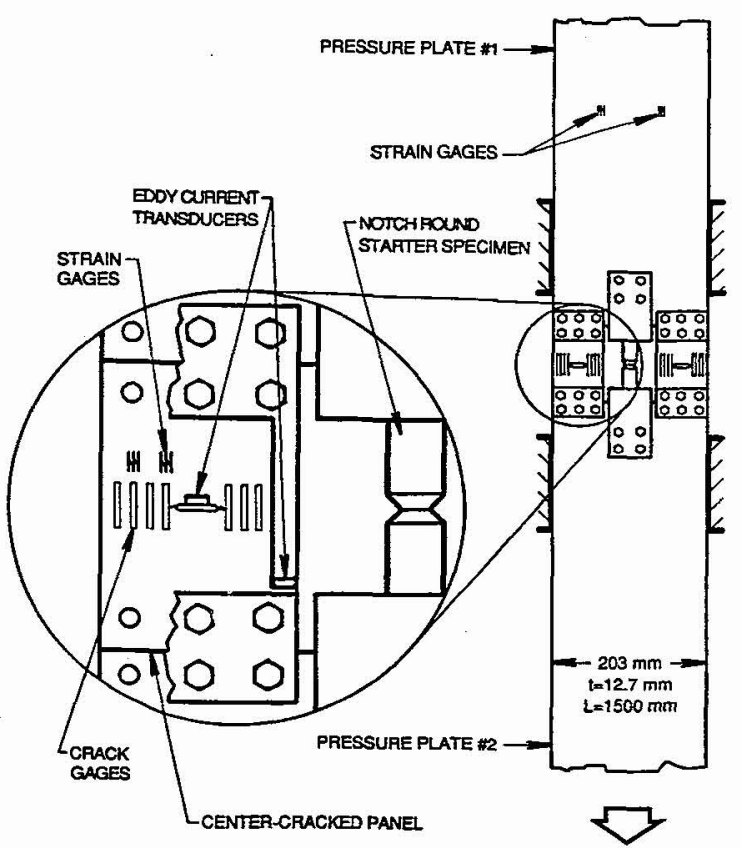

Figure 3. Schematic diagram of the coupled pressure plates experiment. 
The specimen crack length was chosen such that crack initiation occurred during the failure of the starter. During this time period, 100-120 $\mathrm{s}$, a monotonically increasing load is applied to the specimen arms corresponding to a stress intensity rate, $\mathrm{K}_{\mathrm{I}}$, of about $1 \times 10^{6} \mathrm{MPa} \sqrt{\mathrm{m} \mathrm{s}} \mathrm{s}^{-1}$. The subsequent rapid crack propagation event then occurs during the final unloading of the two separated pressure bars. The crack opening displacement, $\operatorname{COD}(\mathrm{t})$, and the far-field displacement, $\mathrm{FFD}(\mathrm{t})$, histories were monitored using eddy current transducers, see Figure 3. Similar to the static specimens, two strain gages were mounted over the specimen ligament to monitor crack initiation and propagation events. The crack initiation time was deduced from the strain record of the strain gage placed above the prefatigued crack tip by identifying the unloading compressive wave resulting from the initiation of the prefatigued crack [7]. Physical crack growth data were gathered on one side of the specimen using a ladder-type gage having five to ten lines, spaced 3 $\mathrm{mm}$ apart. The load history was deduced from the specimen strain records using load-specimen strain correspondences generated with the quasi-static test.

Because fracture in these center-cracked panels occurred under intermediate to large scale yielding conditions [7], the toughness was calculated using the commonly used nonlinear fracture mechanics parameter, the J-integral. It is important to note that the J-integral has been rarely used to generate plane stress fracture toughness data. This is reflected by the lack of an ASTM standard for plane stress fracture toughness testing. The main reason is that the majority of engineering studies that require plane stress toughness data involve testing of large fracture specimens. For large specimens, plasticity is contained (small scale yielding conditions) and the linear strain energy release rate criterion, $G$, is readily applicable; ASTM standard E561-86 [8] applies. Where complex dynamic loading devices are employed, the need to test small specimens became a requirement. For dynamic fracture specimens, testing conditions do not satisfy ASTM E561-86. However, with the use of the J-integral, the generation of material toughness data using small specimens is possible. The $\mathrm{J}$ value at a given load was calculated from the load-COD record using the equation:

$$
\mathrm{J}=\mathrm{J}_{\mathrm{e}}+\mathrm{J}_{\mathrm{p}}=\left[\{\mathrm{P} \sqrt{\pi \mathrm{a}} /(\mathrm{WB})\} \mathrm{F}_{1}\left(\mathrm{a} / \mathrm{W}, \mathrm{h}_{\mathrm{e}} / \mathrm{W}\right)\right]^{2} / \mathrm{E}+0.5\left\{\eta \mathrm{A}_{\mathrm{PL}} /(\mathrm{Bb})\right\}
$$

where $J_{e}$ and $J_{p}$ are the elastic and plastic component of $J$, respectively, $P$ is the applied load, $F_{1}\left(a / W, h_{e} / W\right)$ is a geometry factor [11], $\eta$ is equal to 2 [12], $B$ is the plate thickness, $a$ and $b$ are the half crack and remaining ligament lengths, respectively, and $A_{P L}$ is the area under the load-COD curve as defined in E813 [8]. The equivalent stress intensity factor was calculated by considering the small scale yielding relation under plane stress conditions:

$$
\mathrm{K}_{\mathrm{IJ}}=\sqrt{\mathrm{EJ}}
$$

where $E$ is the Young's modulus. The validity of the results was evaluated based on an adaptation of the Paris criterion [13] to dynamic plane stress loading conditions:

$$
\mathrm{b} / 2>\alpha \mathrm{J} / \sigma_{\mathrm{y}}
$$

where $b$ and $\sigma_{y}$ are the total remaining ligament length and the yield stress, respectively. For the quasi-static and dynamic fracture toughnesses, a yield stress at a strain rate of $10^{-4}$ and $10^{3} \mathrm{~s}^{-1}$ was applied to Equation (3) [6]. Because no ASTM standard provides a value of $\alpha$ for plane stress J testing, the work of Ernst, et al. [14] was used. Ernst, et al. derive a value of 65 for $\alpha$ based on data generated with a 5 mm thick 2024-T351 aluminum alloy of comparable strength (yield stress $=317 \mathrm{MPa}$, ultimate tensile strength $=440 \mathrm{MPa}$ ) to the 2219-T87 aluminum alloy. The value of $\alpha$ was motivated from tests conducted up to a toughness of $120 \mathrm{MPa} \sqrt{\mathrm{m}}$ with center-cracked panel, compact tension, and single edge notched specimens of initial crack length equal to $25 \mathrm{~mm}$ and of planar size varying from 50 to $100 \mathrm{~mm}$. Using the small-scale yielding relation under plane stress conditions, Equation (2), Ernst, et al. found that J-R curves and K-resistance (K-R) curves correspond to the maximum load. The applicability of the quasi-static analytical approach to the dynamic regime was motivated based on in-depth studies of the companion CPB experiment, and numerical studies [9]. In these studies, the effect of stress wave, inertia, and rate sensitivity material characteristics on toughness measurements was assessed. Because stress waves in the CPB and CPP specimens are generated from the fracture process alone, no significant variation of the toughness due to stress waves has been observed [9]. Numerical studies involving dynamic finite element fracture codes indicate no significant effect of inertia and rate sensitivity material characteristics on dynamic plane strain initiation toughness measurements [15]. For crack propagation, analytical toughness data were found to overestimate the toughness for low-strength high-toughness material, For a rate-sensitive A533-B steel of dynamic yield stress equal to $500 \mathrm{MPa}$, the propagation toughness of $200 \mathrm{MPa} \sqrt{\mathrm{m}}$ overestimates the propagation toughness by $15 \%$ [16]. Therefore, it is anticipated that plane stress dynamic propagation J-toughness calculated with the current approach overestimate the dynamic J-toughness by $15 \%$ for toughness exceeding 150 $\mathrm{MPa} \sqrt{\mathrm{m}}$.

\section{RESULTS}

Under quasi-static and dynamic loading conditions, $\mathrm{a}^{\circ}$ shear fracture was observed, clearly indicating that Mode I fracture occurs under plane stress conditions. Due to precautions taken, the fracture specimens did not exhibit any evidence of crack-tip buckling. Results are given below for one crack side of the quasi-static specimen and for one crack side of one of the dynamic specimens.

The load-COD curve for the quasi-static fracture specimen tested at a constant far field displacement rate of $10^{-6} \mathrm{~m}$ $\mathrm{s}^{-1}$ is shown in Figure 4. As indicated in the figure, the prefatigued crack initiates before the maximum load point. Subsequent crack propagation occurs at a constant crack velocity of $2.5 \times 10^{-5} \mathrm{~m} \mathrm{~s}^{-1}$. The specimen strain histories at $12.7 \mathrm{~mm}$ above the left ligament at the prefatigued crack tip and at $9 \mathrm{~mm}$ from the prefatigued crack tip are given in Figure 5. No residual strains were recorded after complete fracture, i.e., load equal to zero, indicating that plastic deformation in the fracture specimen is contained. Figure 6 shows the quasi-static J-R curve. The quasi-static crack 


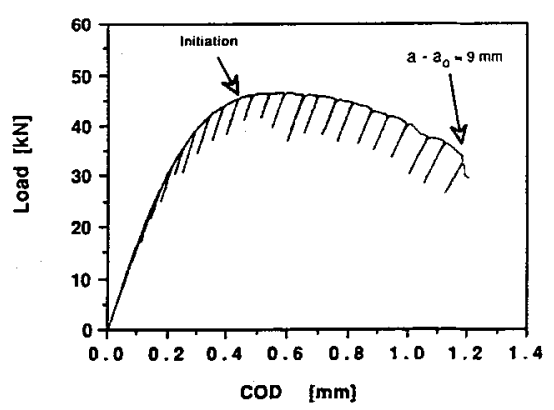

Figure 4. Load-COD response for the quasi-static specimen.

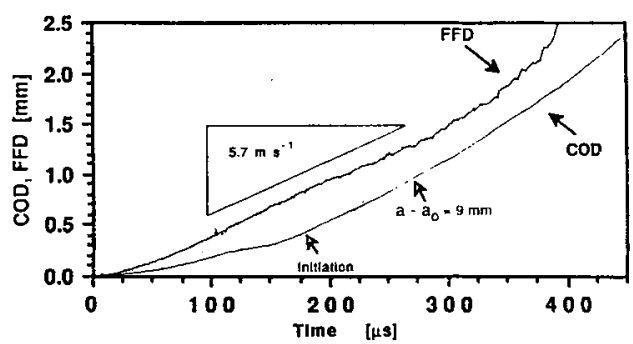

Figure 7. COD and FFD histories for the dynamic specimen.

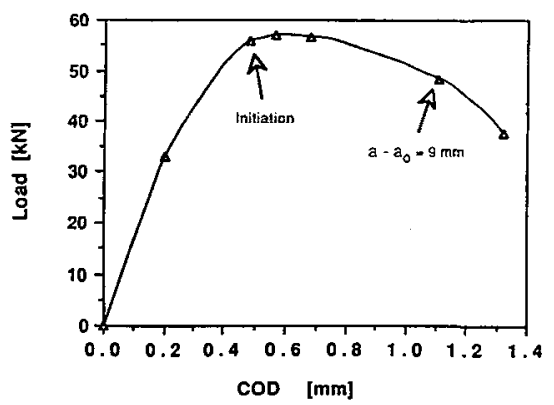

Figure 10. Load-COD response for the dynamic specimen.

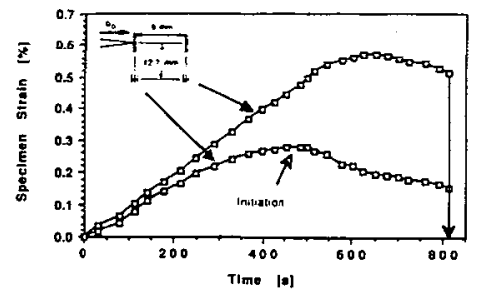

Figure 5. Quasi-static specimen strain histories.

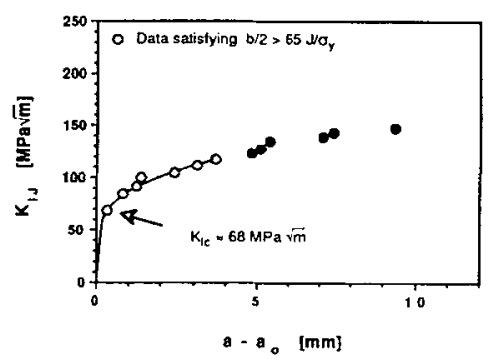

Figure 6. Quasi-static J-R curve.

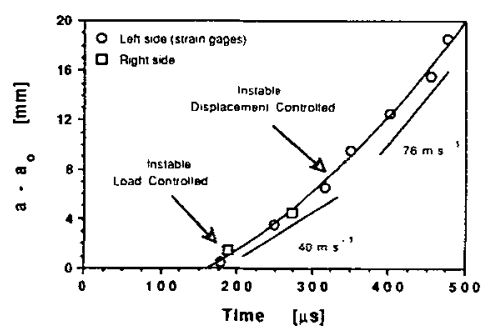

Figure 8. Crack growth histories for the dynamic specimen.

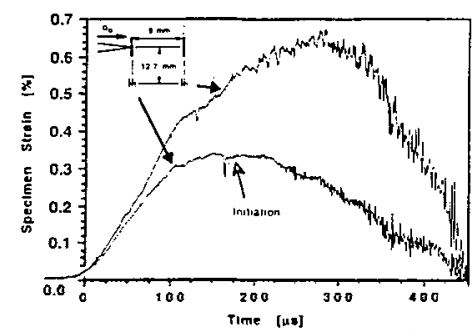

Figure 9. Dynamic specimen strain histories.

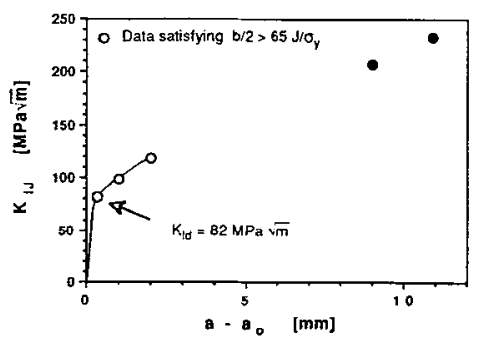

Figure 11. Dynamic J-R curve. 
initiation toughness, corresponding to the onset of crack growth, is equal to $68 \mathrm{MPa} \sqrt{\mathrm{m}}$. At the maximum load the toughness is equal to $92 \mathrm{MPa} \sqrt{\mathrm{m}}$ and coincides with a crack growth of $17.6 \mathrm{~mm}$. This toughness corresponds to the maximum toughness of a center-cracked specimen tested at a constant loading rate and is commonly refered to the specimen "critical toughness". This toughness is related to the specimen driving force implying that it is not a material property. Beyond the maximum load point, stable crack growth occurs only under displacement control with the point of instability being dictated by the specimen compliance.

Figure 7 shows the COD and FFD versus time for one dynamic CCP specimen. Clearly, the CPP technique provides a far-field constant displacement rate of $5.7 \mathrm{~m} \mathrm{~s}^{-1}$. The crack versus time record is provided in Figure 8 . Low crack velocities, $40-76 \mathrm{~m} \mathrm{~s}^{-1}$, were recorded when compared to plane strain crack velocities measured in steel under similar dynamic loading conditions which can reach 200 to $700 \mathrm{~m} \mathrm{~s}^{-1}$ [9]. Note that unstable crack growth under displacement control begins when the crack velocity increases from about 40 to $76 \mathrm{~m} \mathrm{~s}^{-1}$ [7]. Similar to quasi-static loading conditions, the crack velocity is about ten times the far-field displacement rate. Figure 9 shows the specimen strain records. No residual strains were recorded after complete fracture, therefore, indicating that plastic deformation in the center-cracked specimen is contained at both loading rates.

The loading history of the dynamic fracture specimen was derived from the elastic strain measurments conducted on the quasi-static and dynamic specimens. Precisely, the dynamic load, $P_{d i}\left(t_{d}\right)$ at time $t_{d}$ was deduced using:

$$
P_{d i}\left(t_{d}\right)=P_{s i}\left(t_{s}\right) \times \varepsilon_{d i}\left(t_{d}\right) / \varepsilon_{\text {si }}\left(t_{s}\right)
$$

where $\varepsilon_{d i}\left(t_{d}\right)$ is the dynamic elastic strain at time $t_{d}$, and $P_{s i}\left(t_{s}\right), \varepsilon_{s i}\left(t_{s}\right)$ are the static load and the quasi-static elastic strain at time $t_{s}$, respectively. Dynamic loads were calculated using Equation (4) for the following events, $i, i=1$, end of the linear strain increase with time; $i=2$, peak of strain of the strain gage located at a distance of 12 mm above above the prefatigued crack tip; $i=3$, maximum load; $i=4$, peak of strain of the strain gage located $10 \mathrm{~mm}$ ahead and $12 \mathrm{~mm}$ above the prefatigued crack tip. For $\mathrm{i}=2$ and for $\mathrm{i}=3$ and 4 , the strain ratio, $\varepsilon_{\mathrm{di}}\left(\mathrm{t}_{\mathrm{d}}\right) / \varepsilon_{\mathrm{si}}\left(\mathrm{t}_{\mathrm{s}}\right)$, was found to be equal to 1.20 and 1.12 , respectively. The instant at which the load of the dynamic specimen is maximum $\left(t_{d}\right.$ for $\left.i=3\right)$ was derived from local strain measurments conducted on the upper pressure plate above the specimen grips and was found to occur $13 \mu \mathrm{s}$ after crack initiation. The deduced load-COD curve for the dynamic specimen is shown in Figure 10. Similar to quasi-static conditions, crack initiation occurs before the maximum load point. Figure 11 shows the dynamic J-R curve. The dynamic crack initiation toughness is equal to $82 \mathrm{MPa} \sqrt{\mathrm{m}}$ while the toughness at the maximum load associated with a crack growth of $17.0 \mathrm{~mm}$ is equal to $98 \mathrm{Mpa} \sqrt{\mathrm{m}}$. As under quasi-static conditions, beyond maximum load stable dynamic crack growth occurs only under displacement-controlled loading conditions. Figure 12 compares the quasi-static and dynamic J-R curves. For data satysfying Equation (3), the quasi-static J-R curve is lower than the dynamic $J-R$ curve corresponding to about $4 \mathrm{~mm}$ in crack growth. Most propably, this trend prevails over $10 \mathrm{~mm}$ in crack growth and can be verified from numerical simulations of the dynamic specimen using a dynamic finite element fracture code.

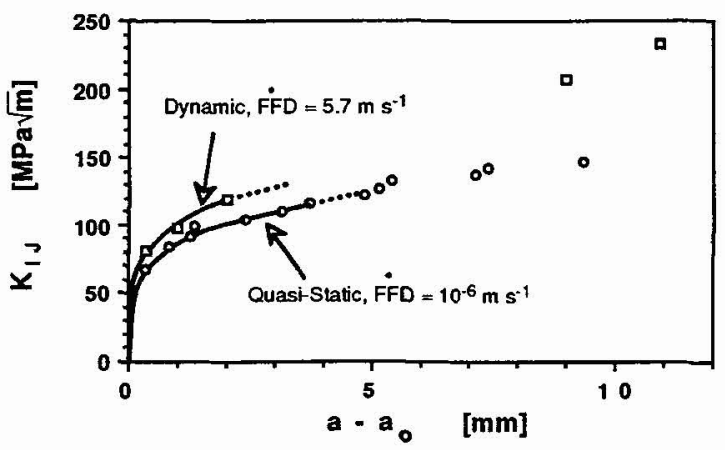

Figure 12. Quasi-static and dynamic J-R curves of the $3.2 \mathrm{~mm}$ thick 2219-T87 aluminum alloy plate.
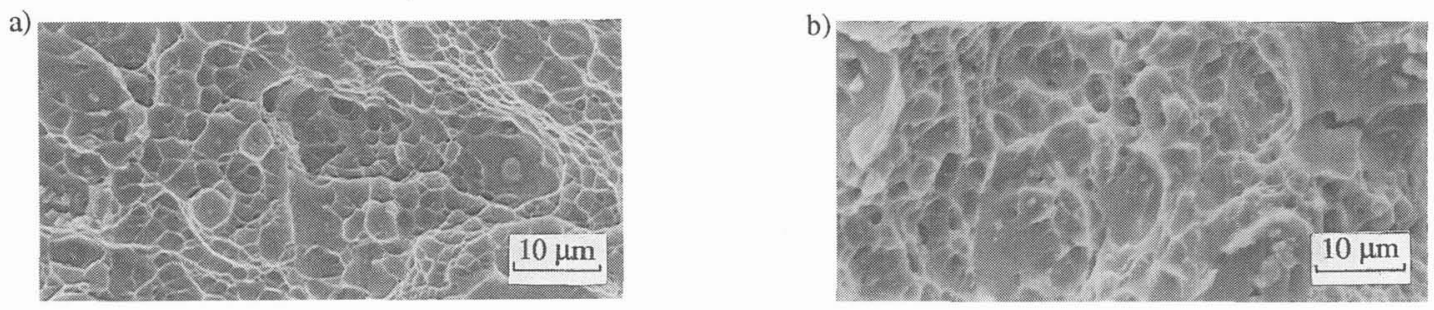

Figure 13. Fractographs of the a) quasi-static and b) dynamic fracture specimens showing the vord structure at initiation. 


\section{DISCUSSION}

Figure 13 shows scanning electron fractographs of the quasi-static and dynamic fracture specimens. At both rates, a fibrous fracture involving a void coalescence and growth failure process occurs for crack initiation and propagation. A similar void size distribution along with a constant average void size of about $5 \mu \mathrm{m}$ were observed. Along with a similar void size distribution, similar CODs at initiation were recorded under quasi-static and dynamic loading conditions; i.e., 0.42 and $0.45 \mathrm{~mm}$, respectively (recall Figures 4 and 10). Similar results were found for quasi-static and dynamic ductile fracture of a 1020 steel [6]. In this study the upper-shelf plane strain initiation toughness was found to increase by $30 \%$ as the rate of change of the stress intensity factor, $\mathrm{K}_{\mathrm{I}}$, increased from 1 to $10^{6} \mathrm{MPa} \sqrt{\mathrm{m} \mathrm{s}}{ }^{-1}$. The mechanisms of fracture initiation for a specific microstructure, which involved void coalescence and growth, were found to be rate independent. Specifically, the void distribution, $\mathrm{COD}$, and critical strain for void formation were found to be constant at both loading rates. These results are consistent with the notion that in a given microstructure:

$$
\mathrm{K}_{\mathrm{Ic}} \sim \sqrt{\text { strength }}
$$

Because the average void size and the COD were found to be rate independent, the toughness-strength dependence given by Equation (5), prevailed for the plane stress fracture toughness of the 2219-T87 aluminum alloy over a wide range of loading rate. This toughness-strength dependance was also confirmed over a wide temperature range from -250 to $23^{\circ} \mathrm{C}[7]$ implying that fracture in this aluminum alloy is a thermally activated process.

\section{CONCLUSIONS}

The effect of loading rate on the plane stress fracture toughness properties of a $3.2 \mathrm{~mm}$ thick 2219-T87 aluminum alloy was investigated from quasi-static to stress wave loading conditions encountered in impacted aluminum structures. A dynamic fracture experiment, named the coupled pressure plates technique (CPP), was implemented to provide a constant displacement rate of $5.7 \mathrm{~m} \mathrm{~s}^{-1}$ to prefatigued center-cracked panels, $76 \mathrm{~mm}$ in planar size. Specific conclusions based on this study are as follows:

1) Under quasi-static and dynamic loading conditions, Mode I fracture involves identical $45^{\circ}$ shear fracture. Under dynamic loading conditions, crack velocities range from 40 to $76 \mathrm{~m} \mathrm{~s}^{-1}$.

2) The plane stress fracture initiation toughness increases by $21 \%$ as the rate of change of the stress intensity factor, $\dot{\mathrm{K}}_{\mathrm{I}}$, increased from 1 to $1 \times 10^{6} \mathrm{MPa} \sqrt{\mathrm{m} \mathrm{s}^{-1}}$.

3) The dynamic J-resistance curve exceeds the quasi-static J-resistance curve.

4) The increase of the plane stress initiation fracture toughness with the increase of loading rate relates to a void coalescence and growth failure process independent of loading rate.

\section{ACKNOWLEDGMENTS}

Plate samples were contributed by the NASA George C. Marshall Space Center. The author is indebted to Dr. Stephen Hudak Jr. for his valuable comments and Mr. Vic Aaron for his technical support. This work was supported by the Grumman Space Station Integration Division under contract 64-00133. Dr. Bernard Lutz served as the technical monitor.

\section{REFERENCES}

1. Holt D. L., Babcock S. G., Green S. J., and Maiden C. J.,Trans. ASM, Vol.60, (1967) pp. 152-159.

2. Lindholm U. S. and Yeakley L. M., Exp. Mech., (1968) pp. 1-9.

3. Lindholm U. S., Bessey, R. L., and Smith G. V., J. Mat., Vol. 6, No. 1, (1971) pp. 119-133.

4. Nicholas T., Exp. Mech., 21, (1981) pp. 177-185.

5. Chiem C. Y., Lee W. S., and Meyer P., DYMAT 88 Conference, J. Phys., T. 49, (1988) pp. 19-28

6. Couque H., Asaro R. J., Duffy J., and Lee, Met. Trans. A, Vol. 22 A, (1988) pp. 2219-2206.

7. Couque H., submitted to Met. Trans. A.

8. ASTM 561-86, Standard Practice for R-Curve Determination; ASTM E 813-87, Standard Test Method for J $J_{\text {Ic }}$, A Measure of Fracture Toughness; ASTM E 1152-87, Standard Test Method for Determining J-R Curves, Vol. 03.01, Annual Book of ASTM Standards (1993).

9. Couque H., Hudak S. J. Jr., and Lindholm U. S., DYMAT 88 Conference, J. Phys., T. 49, (1988) pp. 347-352.

10. Couque H., Leung C. P., and Hudak S. J. Jr., Eng. Fract. Mech., Vol. 47, No. 2, (1994) pp. 249-267.

11. Tada H., Paris P. C., and Irwin R., The Stress Analysis of Cracks Handbook (Paris Productions, Inc., 1985).

12. Hutchinson J. W., and Paris P. C., ASTM STP 668, (1979) pp. 37-64.

13. Paris P. C., in written discussion to Landes J. D. and Begley J. A., ASTM-STP 514, (1972) pp. 24-39.

14. Ernst H. A., Schwalbe K. H., Hermann D., and McCabe D. E., Int. J. Fract., No. 37, (1988) pp. 83-100.

15. Moran B., Asaro R. J., and Shih C. F., Met. Trans. A, Vol. 22A, (1991) pp. 161-170.

16. Bass B. R., Keeney-Walker J., Dickinson T. L., Pugh C. E., Schwartz C. W. and Theskens J. C., Comp. and Struct., Vol. 32, No. 34, (1989) pp. 815-824. 